\title{
Evaluación del efecto de dos anticoagulantes sobre el desarrollo bacteriano en hemocultivos
}

\section{INSTITUTO DE MICROBIOLOGIA CLINICA FACULTAD DE MEDICINA UNIVERSIDAD AUSTRAL DE CHILE}

Debido a la alta frecuencia de Septicemias y a la elevada mortalidad, que alcanza hoy en día del orden del 20 al $25 \% \%^{(6)}$ y entre el 60 y $80 \%$ cuando se presenta shock, ${ }^{(2)}$ es que los bacteriólogos tienen una preocupación permanente por mejorar la técnica del Hemocultivo con el fin de obtener cada vez mejores resultados y en un menor tiempo.

El procesamiento de las muestras de sangre para cultivo es una de las técnicas microbiológicas más variadas. Así la amplia variedad de frascos para Hemocultivos, equipos de toma de muestra, medios de cultivo y sustancias adicionales, hacen casi imposible una uniformidad de criterio.

Uno de los mayores problemas a que se enfrenta el laboratorista son los factores bactericidas normales del suero, que matan a las bacterias en el término de segundos, ${ }^{(5)}$ de modo que a menos que este efecto se diluya o se neutralice de inmediato, se impedirá o retardará el crecimiento de cualquier bacteria de una muestra de sangre. Una manera de contrarrestar estos efectos es diluyendo la sangre en caldo de cultivo en una proporción de al menos 1:20. Otra forma es adicionándole sustancias neutralizadoras como Citrato de sodio, Heparina o Polianetol sulfonato de sodio, que a la vez sirven de anticoagulantes. $^{(6)}$

Sin embargo algunas de estas sustancias resultan ser tóxicas para un determinado grupo de microorganismos. Rammell ${ }^{(7)}$ demostró el efecto tóxico del Citrato de Sodio sobre los Staphylococcus. ${ }^{(1)}$ Von Haebler y Miles ${ }^{(4)}$ demos- traron que la mayoría de las bacterias sobreviven un tiempo mucho mayor en Hemocultivos que contengan Polianetol sulfonato de sodio como anticoagulantes en vez de Citrato de sodio.

Existen en la actualidad una serie de trabajos realizados con muestras clínicas y en forma experimental, que indican claramente la eficacia del Polianetol sulfonato de sodio como el mejor anticoagulante. $(1,3,8,9,11)$

Teniendo como antecedentes los trabajos de Rammell( ${ }^{(7)}$ y Rosner, ${ }^{(9)}$ en el que el Citrato de sodio al $1 \%$ resulta inhibidor para bacterias Gram positivas y que el Polianetol sulfonato de sodio es considerado como el mejor anticoagulante, es que nos propusimos evaluar los rendimientos de los Hemocultivos utilizando Citrato de sodio a una concentración diez veces más baja que lo habitual, en comparación con el Polianetol sulfonato de sodio a una concentración de $0,03 \%$.

\section{MATERIAL Y METODO}

Se recolectaron entre abril y septiembre de 1975, 164 muestras provenientes de 57 pacientes pediátricos con diagnóstico probable de Septicemia.

Se inocularon 2 a $5 \mathrm{ml}$. de sangre en un frasco de Hemocultivo con $70 \mathrm{ml}$. de Caldo Tripticasa de soja con Citrato de sodio al $0,1 \%$. En otro frasco, conteniendo la misma cantidad de Caldo de cultivo utilizando Polianetol sulfonato de sodio al $0,03 \%$ como anticoagulante, se inocularon los 2 a $5 \mathrm{ml}$. restantes..$^{(1,8)}$

Los frascos inoculados eran incubados a $35^{\circ}$ C y se examinaron periódicamente durante 14 días. ${ }^{(3)}$ Toda unidad sin evidencia de desarrollo era resembrada cada 48 hrs. a placas de Agar 
chocolate e incubadas en una atmósfera de $\mathrm{CO}_{2}$ al 5 a $10 \%$.

\section{RESULTADOS}

De las 164 muestras estudiadas, se obtuvieron 60 hemocultivos positivos, lo que da un $36,58 \%$ y 104 hemocultivos negativos que corresponden a un $63,4 \%$, lo que se encuentra detallado en la Tabla N..$^{\circ} 1$.

\section{Tabla N.' 1}

Número y porcentaje de hemocultivos positivos y negativos

\begin{tabular}{l|c|c}
\hline Hemocultivos & Número & Porcentaje \\
\hline Positivos & 60 & 36,58 \\
Negativos & 104 & 63,4 \\
\hline Total & 164 & 100 \\
\hline
\end{tabular}

La Tabla N. ${ }^{\circ} 2$ muestra el número y porcentaje de muestras positivas para cada anticoagulante.

\section{Tabla N.․ 2}

Número y porcentaje de muestras positivas para cada anticoagulante

\begin{tabular}{l|cc}
\hline \multirow{2}{*}{ Método aplicado } & \multicolumn{2}{|c}{ Resultados } \\
\cline { 2 - 3 } & Número & Porcentaje \\
\hline Citrato de Na & 48 & $80 \%$ \\
Liquoid & 54 & $90 \%$ \\
\hline Citrato y Liquoid & 42 & $70 \%$ \\
\hline
\end{tabular}

De los 60 Hemocultivos positivos un $80 \%$ lo fueron en el medio con Citrato de sodio y un $\mathbf{9 0 \%}$ en el medio Liquoid.

El desglose de estos datos y la comparación del Citrato de sodio versus Polianetol sulfonato de sodio se encuentran detallados en la Tabla N. ${ }^{\circ}$ 3.
Tabla N.․ 3

Frecuencia de Hemocultivos positivos y negativos para cada anticoagulante

\begin{tabular}{l|c|c|c}
\hline \multirow{2}{*}{ Citrato de sodio } & \multicolumn{3}{|c}{ Liquoid } \\
\cline { 2 - 4 } & + & - & Total \\
\hline+ & 42 & 6 & 48 \\
\hline- & 12 & 104 & 116 \\
\hline Total & 54 & 110 & 164 \\
\hline
\end{tabular}

De las 48 muestras positivas para Citrato de sodio, 42 de ellas lo fueron en el estudio con ambos anticoagulantes. 6 de las 48 fueron positivas sólo en el medio con Citrato de sodio.

De las 54 muestras positivas para Polianetol sulfonato de sodio, 12 lo fueron solamente en el medio con este anticoagulante.

Los microorganismos aislados con cada anticoagulante se detallan en la Tabla N. ${ }^{\circ} 4$.

Tabla N.' 4

Frecuencia de Microorganismos aislados con cada anticoagulante

\begin{tabular}{l|c|c|c}
\hline \multirow{2}{*}{ Microorganismos } & \multicolumn{3}{|c}{ METODO } \\
\cline { 2 - 4 } & $\begin{array}{c}\text { Citrato } \\
\text { de sodio }\end{array}$ & Liquoid & Ambos \\
\hline Staphylococcus aureus & 7 & 10 & 6 \\
Staphylococcus & & & \\
epidermidis & 3 & 3 & 3 \\
Streptococcus & & & \\
pneumoniae & 6 & 3 & 3 \\
Bacillus subtilis & 1 & 1 & 1 \\
Salmonella Grupo C & 1 & 1 & - \\
Klebsiella sp. & 2 & 2 & 2 \\
Mima polymorpha & 2 & 6 & 2 \\
Escherichia coli & 6 & 8 & 5 \\
Pseudomonas cepacia & 7 & 7 & 7 \\
Pseudomonas aeruginosa & 3 & 3 & 3 \\
Enterobacter sp. & 5 & 5 & 5 \\
Alcaligenes faecalis & 1 & 1 & 1 \\
Providence & 1 & 1 & 1 \\
Salmonella typhi & 1 & 1 & 1 \\
Bacilos Gram negativos & & 2 & 2 \\
no iden'ificados & 2 & 2 & 2 \\
\hline Total & 48 & 54 & 42 \\
\hline
\end{tabular}


El número de aislamientos para bacterias Gram positivas y negativas con cada anticoagulante se encuentran detallados en la Tabla N. 5.

\section{Tabla N.0 5}

\section{Número y porcentaje de microorganismos Gram negativos y positivos aislados con cada anticoagulante}

\begin{tabular}{l|r|c|c|c}
\hline \multirow{2}{*}{ Microorganismos } & \multicolumn{2}{|c|}{$\begin{array}{c}\text { Citrato de Na } \\
(48)\end{array}$} & \multicolumn{2}{|c}{$\begin{array}{c}\text { Liquoid } \\
(54)\end{array}$} \\
\cline { 2 - 5 } & N.0 & $\%$ & N. & $\%$ \\
\hline Grim positivos & 17 & 80,9 & 17 & 80,9 \\
Gram negativos & 31 & 79,48 & 37 & 94,87 \\
\hline
\end{tabular}

De la Tabla N. ${ }^{\circ} 5$ se observa que no existe diferencia en el aislamiento de bacterias Gram positivas con ambos anticoagulantes. Para bacterias Gram negativas se observa un mayor aislamiento en el medio con Liquoid del orden del $14,5 \%$.

\section{DISCUSION}

Teniendo en cuenta el efecto tóxico del Citrato de sodio reportado por Rammell y Rosner, hemos probado un modelo con Citrato de sodio al $0,1 \%$, concentración diez veces menor que la utilizada habitualmente. Al comparar nuestros hallazgos con el medio de Hemocultivo con Liquoid, se observa que respecto de las bacterias Gram positivas no hay diferencias en el porcentaje de aislamiento con uno $u$ otro anticoagulante. Ello indica de acuerdo a los antecedentes previos que el Citrato de sodio a esta concentración y sin haber perdido su efecto anticoagulante, no estaría manifestando su efecto inhibidor.

Rosner ${ }^{(9)}$, utilizando medios de cultivo con una concentración final de Citrato de sodio al $1,4 \%$ y Liquoid en la misma concentración de nuestro estudio, encontró un $50 \%$ menos de aislamiento para bacterias Gram positivas en el medio con Citrato de sodio respecto del medio con Liquoid. Evans ${ }^{(1)}$ reporta una drástica inhibi- ción de Streptococcus pyogenes y Staphylococcus aureus en Hemocultivos experimentales con Citrato de sodio al 1\%. Los hechos anteriores apoyan nuestra hipótesis de trabajo y las evidencias prestadas, ya que si se observa la Tabla N.o 4, se aprecia que para Streptococcus pneumoniae hubo un mayor aislamiento en los medios con Citrato de sodio.

Respecto de las bacterias Gram negativas, se observó una diferencia significativa en el número de aislamiento al aplicar la prueba $T$ de Student $(p<0,01)$. Nuestros resultados son aproximadamente un $29 \%$ superiores a lo reportado por Rosner ${ }^{(9)}$ respecto al medio de Hemocultivo con Citrato de sodio.

Al comparar los resultados de los medios con Citrato de sodio versus Medios con Liquoid (ver Tabla N. ${ }^{\circ} 3$ ), se comprobó mediante el Test de ji cuadro $(p<0,05)$ que existen diferencias signifi cativas entre ambos métodos, lo cual haría aconsejable la incorporación del Polianetol sulfonato de sodio en Hemocultivos en nuestro país. Sin embargo, pensamos que utilizando el Citrato de sodio a la concentración de $0,1 \%$, se lograrian mejores resultados que con las concentraciones actualmente en uso.

\section{REFERENCIAS}

1 Evans, G. L., et al. 1968. Comparative effects of anticoagulants on becterial growth in experimental blood culture. Am. Jour of Med. Tec. Vol. 34, N. ${ }^{\circ}$.

${ }^{2}$ Hall, W.H., and Gold, D. 1955. Shock associated with bacteriemia: review of 35 cases. Arch. Intern. Med. 96: 403412.

${ }^{3}$ Hall, M.; Warren, E. Washington 11, J.A. 1974. Detection of bacteriemia with Liquoid media containing Sodium polywnethol sulfonate, Appl. Mic. 27: 187-191.

4 Von Haebler, T., and Miles, A.A. 1938. The action of sodium polyanethol sulfonate (Liquoid) on blood culture. J. Path. Bact. 46: 245-252.

5 Lowrance, B.L and Traub, W.H. 1969 . Inactivation of the bactericidal activity of human serum by Liquoid. Appl. Mic. 17: 839 .

${ }^{6}$ Merril, S.L.; A. Davis, B. Smolens and S. M. Finegold. 1966. Cephalothin in serious bacterial infection, Am. Intern. Med. 64: 1-12.

${ }^{7}$ Rammell, C.G. 1862 . Inhibition by citrate of the growth of congulase positive staphylococci. J. Bact. 84: 1123-1124.

${ }^{8}$ Rosner, R.A. 1872. A quantitative evaluation of three blood culture systems. Am. Jour. Clin. Path. 57, 2.

${ }^{9}$ Rosner, $R$. 1967. Efect of various anticoagulants and no anticoagulant on ability to isolate bacteria directly from parallel clinical blood specimens. Am. Jour. Clin. Path. 49: 216-219.

10 Sonnenwirth, A.C. y Col. Bacteriemia, Aspectos clínicos y de laboratorio. Editorial Médica Panamericuna. 1975.

11 Stuurt, R.D. 1948. The Value of Liquoid for blood culture. J. Clin. Path. 1-311. 
Se evalúa el rendimiento de hemocultivo utilizando como anticoagulantes Citrato de sodio al $0,1 \%$ y Polianetol sulfonato de sodio al $0,03 \%$. No se observan diferencias en los aislamientos para bacterias Gram positivas.

Para las bacterias Gram negativas se obtuvo una mayor aislamiento en el medio con Liquoid del orden del $14,5 \%$, lo que nos lleva a preconizar la utilización en nuestro medio de este anticoagulante.

Sin embargo, utilizando el Citrato de sodio a la concentración probada ( 10 veces inferior a la utilización normalmente) se logran mejores resultados que con las concentraciones actualmente en uso.
A comparison of the hemocultures with sodium polyanethol sulfonate $(0.03 \%)$ and sodium citrate $(0.1 \%)$ as anticoagulants is conducted.

Not differences is observed with both anticoagulants in the isolation of Gram positive bacteria.

For the Gram negative rods we obtain a better isolation in the hemocultures with sodium polyanethol sulfonate in a range of $14,5 \%$. Nevertheless our results by the using of sodium citrate at $0,1 \%$ suggest the use of this modification in the hemoculture in our country when sodium polyanethol sulfonate not is available. 